\title{
Fizyoterapistlerde Empati Becerisinin Mutluluk ve Tükenmişlik Düzeyi ile İlişkisi
}

\author{
DOI: $10.26466 /$ opus.600820
}

\author{
Ayça Aytar Tiğlı* \\ * Dr.Öğr.Üyesi, Başkent Üniversitesi Sağlık Hizmetleri Meslek Yüksekokulu, Terapi ve Rehabilitas- \\ yon Programı, Fizyoterapi, Ankara, Türkiye \\ E-Posta: aycatigli@baskent.edu.tr \\ ORCID: 0000-0002-4089-5406 \\ Öz
}

İletişim becerileri bazı mesleklerde oldukça önemlidir. Özellikle sağlık sektöründe hasta ile sağlıklı ve etkili iletişim tedavinin sonuçların da olumlu etkileyebilmektedir. Sağhlkh bir iletişim için öncelikle kişinin karşısındakini anlayabilmesi, kendisi ile barışık olması ve tükenmişlik yaşamıyor olması gerekmektedir. Bu nedenle çalışmamızın amacı fizyoterapistlerde empati becerisinin mutluluk ve tükenmişlik düzeyi ile ilişkisini incelemek idi. Çalışmaya özel hastanelerde görev yapan ve çalışmaya katılmayı gönüllü olarak kabul eden 90 fizyoterapist alındı. Bireylerin Empati beceri düzeylerini değerlendirmek için Toronto Empati Ölçeği (TEQ), mutluluk düzeyini ölçmek için Oxford Mutluluk Ölçeği Kısa Formu (OMÖ-K) ve mesleki tükenmişlik düzeyini ölçmek üzere Tükenmişlik Ölçeği-Kısa Formu (TÖ-KF) uygulandi. Mutluluğun tükenmişlik düzeyi ile negatif ( $r=-0.678$ ), empati becerileri ile ise pozitif ilişkili $(r=0.212)$ olduğu saptandı ( $p=0.045)$. Çoklu adımsal regresyon analizi sonuçlart ise mutluluğun empati düzeyinin pozitif belirleyicisi $\left(R=0.212,\left(R^{2}=0.045\right)\right.$ olduğunu gösterdi. Empati ve empatik yaklaşımın kişilerin tükenmişlik ve mutluluk düzeyleri ile ilişkisi göz önünde bulundurulduğunda bunları etkileyen faktörlerin erken dönemde fark edilmesi ve önlemeye yönelik tedbirlerin alınması hizmet kalitesini olumlu yönde etkiler. Ayrica tükenmişliğe neden olan faktörlerin erken dönemde fark edilmesi ve önlemeye yönelik tedbirlerin alınması da oldukça yararlı olabilir.

Anahtar Kelimeler: Empati, Mutluluk, Tükenmişlik 


\title{
The Relationship Between Empathy Skills with Happiness and Burnout Level in Physiotherapists
}

*

\begin{abstract}
Communication skills are very important in some professions. Especially in the health sector, healthy and effective communication with the patient may positively affect the treatment results. First of all, to be able to understand the other person, at peace with himself and not having burnout for a healthy communication. Therefore, the aim of this study was to investigate the relationship between empathy with happiness and burnout levels in physiotherapists. Ninety physiotherapists who were working in private hospitals participated in the study voluntarily. Toronto Empathy Scale was used to determine empathy skills, Oxford Happiness Scale Short Form to measure happiness and Burnout Scale-Short Form to measure professional burnout levels. It was found that happiness was negatively correlated with burnout level $(r=-0.678)$ and positively correlated with empathy skills $(r=0.212, p=0.045)$. Multiple stepwise regression analysis showed that happiness was a positive predictor of empathy $(R=0.212$, $\left(R^{2}=0.045\right)$. Considering the relationship between empathy and empathic approach and burnout and happiness levels of individuals, early recognition of the factors affecting them and taking preventive measures have a positive effect on service quality. It may also be useful to recognize the factors causing burnout in the early period and to take preventive measures.
\end{abstract}

Keywords: Empathy, Happiness, Burnout 


\section{Giriş}

Günümüzde pek çok meslek grubu insanlarla yüz yüze iletişim gerektirmektedir. Tükenmişlik, insanlarla yakın ilişki gerektiren mesleklerde çalışanları tehdit eden bir sendromdur ve baş edilemeyen stresin sonucu olarak ortaya çıkmaktadır. Bu da; kişilerin yaşamı üzerinde fiziksel, zihinsel ve duygusal olarak baskı oluşturmakta ve kişilerde tükenmişlik oluşturmaktadır (Çapri, 2006). Tükenmişlik; hem kişileri hem de kişilerin çalışma hayatını olumsuz etkilemektedir (Akbaba, Türkmen, Birinci, 2018). Yalnızca tükenmişlik değil, çalışma ortamının koşullarından memnun olmama durumu ve mesleki memnuniyetsizlik de çalışan kişilerin çalışma hayatlarını ve psikolojilerini etkilemekte bu da onların kaliteli hizmet vermelerini engellemektedir (Akbaba, Türkmen ve Birinci, 2018). Dolayısı ile çalışan kişilerin sadece fiziksel olarak iyi olmaları değil ruhsal olarak da tam bir iyilik hali içinde olmaları oldukça önemlidir.

Psikolojik rahatsızlıklara karşı mutluluğun koruyucu etkisi olduğu söylenmektedir (Özdemir ve Koruklu, 2011). Mutluluk insan yaşamının bütün yönlerini etkileyen bir kavramdır. Genel anlamıla kişinin hissettiği olumlu duyguların olumsuz duygulardan daha fazla olması ve yaşamdan doyum alması olarak ifade edilir (Özdemir ve Koruklu, 2011).

Daha mutlu ve doyumlu ilişkiler yaşamak için ise başkalarını anlamak gereklidir. Kişilerin kendisini karşısındakinin yerine koyarak olaylara onun bakış açısı ile bakması, o kişinin duygularını ve düşüncelerini doğru olarak anlaması ve bu durumu ona iletmesi durumuna empati denir (Dökmen, 1999). Yardım etme düzeyinin belirleyicilerinden biride empatik eğilimdir. Sorunu olan bireylerin duygularını anlayarak onların duygusal yaşantılarından etkilenme yeteneğini içermektedir. Bu nedenle empati ile kişilerarası iletişim ve işbirliği arasında olumlu bir ilişki bulunmaktadır. Fizyoterapistlerin de rehabilitasyon süreci boyunca hastaları ile yakın etkileşimde olmaları gerekebildiği için empati ile kişilerarası iletişim ve işbirliği önem kazanmaktadır (Kılınç ve Uludağ, 2017).

Literatürde sağlık alanındaki farklı meslek gruplarında tükenmişliğin ve empatinin incelendiği çalışmalara rastlanmaktadır (Fields vd., 2004; Lee vd., 2003; Lee, Song, Cho, Lee, ve Daly, 2003). Ancak fizyoterapistlerde yapılan çalışmalar sınırlı sayıda kalmıştır (Tarakcı, Tütüncüoğlu, Tarakc1, 2012). Bu bağlamda, fizyoterapistlerin tedavilerini pozitif duygular 
içerisinde yürütmelerinin tedavi sonuçlarını da olumlu yönde etkileyebileceği düşüncesi ile çalışmamızın amacı fizyoterapistlerde empati becerisinin mutluluk ve tükenmişlik ile ilişkisini incelemek idi.

\section{Yöntem}

\section{Bireyler}

Çalışmamız, Aralık 2018 ve Haziran 2019 tarihleri arasında özel hastanelerde çalışan ve çalışmaya katılmayı gönüllü olarak kabul eden fizyoterapistler üzerinde gerçekleştirildi. Araştırma evrenini Ankara ilinde özel hastanelerde görev yapan fizyoterapistler oluşturur iken çalışma örneklemini yüz yüze anket metodu uygulanabilen 90 fizyoterapist oluşturdu. Çalışmaya en az 1 yıl süre ile aktif bir şekilde fizyoterapist olanlar dahil edilir iken çalışmaya katılmaya gönüllü olmayan bireyler çalışmaya dahil edilmedi.

Çalışmada örneklem büyüklüğü G*Power yazılımı kullanılarak yapıldı. Güç analizine göre \% 85 güç ve 0,05 hata payı ile 77 birey olarak bulundu. Dahil edilme kriterlerine bağlı veri kaybı olabileceği düşünülerek örneklem büyüklüğü \% 15 daha fazla hesaplanarak çalışmaya dahil edilmesi gereken fizyoterapist sayısı toplam 89 olarak belirlendi.

\section{Değerlendirmeler}

Değerlendirmeler yüz yüze görüşerek yapıldı. Öncelikle sosyodemografik durumu belirlemek amaci ile bir bireysel bilgi anketi dolduruldu. $\mathrm{Bu}$ bireysel bilgi anketinde bireylerin boy, kilo, eğitim ve medeni durumu, çalıştıkları semt, çalışma süreleri sorgulandı. Empati beceri düzeylerini değerlendirmek için Toronto Empati Ölçeği (TEQ), mutluluk düzeyini ölçmek için Oxford Mutluluk Ölçeği Kısa Formu (OMÖ-K) ve mesleki tükenmişlik düzeyini ölçmek üzere Tükenmişlik Ölçeği-Kısa Formu (TÖKF) uyguland.

Toronto Empati Ölçeği:Bireylerin empati seviyelerini değerlendirmek için TEQ kullanıldı. Türkçe uyarlaması 13 maddelik beşli Likert tipi (puanlamada sekiz madde tersten kodlanmaktadır) tek boyutlu bir ölçektir. 
Yüksek puanlar yüksek empati düzeyine işaret etmektedir. Ölçeğin Türkçe uyarlaması Totan ve vd. (2012) tarafından yapılmıştır (Totan, Doğan, Sapmaz, 2012).

Oxford Mutluluk Ölçeği Kısa Formu:Bireyin mutluluk düzeyini ölçmek için OMÖ-K kullanıldı. OMÖ-K'nın Türkçe uyarlaması 7 maddelik beşli Likert tipi (1: Hiç Katılmıyorum, 5: Tamamen Katılıyorum) öz bildirim tarzı bir ölçektir. Ölçekten alınan yüksek puanlar mutluluk düzeyinin yüksek olduğunu belirtir. Ölçeğin Türkçe uyarlaması geçerli ve güvenilirdir (Doğan ve Akıncı, 2011).

Tükenmişlik Ölçeği-Kısa Formu (TÖ-KF):Bireylerin mesleki tükenmişlik düzeylerini belirlemek üzere TÖ-KF kullanıldı. 10 maddeden oluşmakta olan ölçek bireyin fiziksel, duygusal ve zihinsel yorgunluk düzeylerini değerlendirir. Bireylerin mesleki tükenmişlik düzeyini ölçmek üzere yedi dereceden (1: Hiçbir zaman, 7: Her zaman) oluşan öz bildirim tarzı bir ölçektir. Yüksek puanlar yüksek tükenmişlik düzeyine işaret etmektedir. Ölçeğin Türkçe uyarlamasının geçerliliği ve güvenilirliği gösterilmiştir (Çapri, 2013).

\section{İstatistiksel Analiz}

Çalışma verileri SPSS Windows 19.0 (IBM SPSS Statistics for Windows, Version 19.0. Armonk, NY: IBM Corp.) programı kullanılarak analiz edildi. Elde edilen veriler ortalama standart sapma $\left(X_{ \pm} S S\right)$ ve sayı $(n \%)$ olarak ifade edildi. Değişkenler arasındaki korelasyon ise "Pearson Korelasyon Analizi" ile değerlendirildi. İstatistiksel anlamlılık düzeyi $\mathrm{p}<0,05$ değeri olarak kabul edildi. Mutluluk ve tükenmişlik düzeylerinin empati becerisinin belirleyicileri olup olmadıklarını test etmek için ise Çoklu Adımsal Regresyon analizi kullanıldı.

\section{Bulgular}

Çalışmamızda 56 kadın, 34 erkek toplam 90 birey (yaşx+ss $=27,56 \pm 5,27$ yıl) değerlendirildi. Bireylere ait sosyodemografik özellikler tablo 1'de verildi. 
Tablo 1. Bireylerin sosyodemografik özellikleri

\begin{tabular}{|c|c|}
\hline & Fizyoterapist $(n=90)$ \\
\hline Yaş $(\mathrm{y} 11, \mathrm{X} \pm \mathrm{SS})$ & $27,56 \pm 5,27$ \\
\hline \multicolumn{2}{|l|}{ Cinsiyet, (n\%) } \\
\hline Kadın & $56(62,2)$ \\
\hline Erkek & $34(37,8)$ \\
\hline Vücut kütle indeksi $\left(\mathrm{kg} / \mathrm{m}^{2}, \mathrm{X} \pm \mathrm{SS}\right)$ & $23,55 \pm 3,34$ \\
\hline \multicolumn{2}{|l|}{ Eğitim durumu, n(\%) } \\
\hline Lisans & $71(78,9)$ \\
\hline Yüksek Lisans & $17(18,9)$ \\
\hline Doktora & $2(2,2)$ \\
\hline \multicolumn{2}{|l|}{ Medeni durumu, (n\%) } \\
\hline Evli & $21(23,3)$ \\
\hline Bekar & $69(76,7)$ \\
\hline Çalışma süresi, yıl ( $\mathrm{X} \pm \mathrm{SS}$ ) & $4,58 \pm 4,91$ \\
\hline Günlük çalışma süresi, saat ( $\mathrm{X} \pm \mathrm{SS}$ ) & $8,39 \pm 1,15$ \\
\hline
\end{tabular}

X: ortalama, SS: standart sapma, n: sayı, \%: yüzde

Yapılan korelasyon analizi sonrasında, mutluluğun tükenmişlik düzeyi ile negatif $(\mathrm{r}=-0.678)$, empati becerileri ile ise pozitif ilişkili $(\mathrm{r}=0.212)$ olduğu saptandı (Tablo 2). Başka bir deyişle, bireylerin mutluluk düzeyleri arttıkça tükenmişlik düzeylerinin düştügünü, empati becerilerinin ise arttığını söyleyebiliriz.

Tablo 2. Empati beceri düzeyi, mutluluk ve tükenmişlik düzeyi arasındaki ilişkiye yönelik korelasyon sonuçları $(n=90)$

\begin{tabular}{lll}
\hline \multirow{2}{*}{ Parametreler } & OMÖ-K & \\
& $\mathrm{P}^{¥}$ & $\mathrm{r}$ \\
\hline TEQ & $0.045^{*}$ & 0.212 \\
TÖ-KF & $0.000^{*}$ & -0.678 \\
\hline
\end{tabular}

${ }^{*} p<0,05,{ }^{*}:$ Pearson Korelasyon Analizi, $r$ : Pearson Korelasyon Katsayısı, TEQ: Toronto Empati Ölçeği, OMÖ-K: Oxford Mutluluk Ölçeği Kısa Formu, TÖ-KF: Tükenmişlik Ölçeği-Kısa Formu

Yapılan çoklu adımsal regresyon analizi sonuçları ise mutluluğun $\left(\mathrm{F}_{1,88}=4.14 ; \mathrm{R}=0.21 ; \mathrm{R}^{2}=0.04 ; \mathrm{p}<0.05\right)$ empati düzeyinin pozitif belirleyicisi olduğunu gösterdi (Tablo3). 
Tablo 3. Empati beceri düzeyi, mutluluk ve tükenmişlik düzeyi arasındaki ilişkiye yönelik yapılan çoklu adımsal regresyon sonuçları $(n=90)$

\begin{tabular}{llll} 
& $\begin{array}{l}\text { TEQ } \\
\mathbf{R}\end{array}$ & $\mathbf{R}^{\mathbf{2}}$ & $\mathbf{B}$ \\
\hline $\begin{array}{l}\text { OMÖ-K } \\
\left(\mathrm{F}_{1,88}=\mathbf{4 . 1 4}\right)\end{array}$ & 0.212 & 0.045 & 0.212 \\
\hline
\end{tabular}

TEQ: Toronto Empati Ölçeği, OMÖ-K: Oxford Mutluluk Ölçeği Kısa Formu, R: Regresyon Katsayısı, $R^{2}$ : R kare, $\beta$ : beta

\section{Tartışma}

İnsanlarla doğrudan etkileşimde olan meslekler de bazı kişilik özellikleri oldukça önemlidir. Özellikle sağlık sektöründe çalışanlarının bu özellikleri; hastaları ve tedavi sonuçlarını da etkilemektedir. Çalışmamızda fizyoterapistlerdeki mutluluğun tükenmişlik ile negatif, empati yeteneği ile ise pozitif yönde ilişkisi olduğu görüldü. Bununla birlikte; mutluluğun empati yeteneği üzerinde belirleyici etkisi olduğu tespit edildi.

Hasta ve yakınlarınlarına empatik yaklaşamama, onlarla etkili iletişim kuramama çalışan kişilerde görevini tam yapamıyor olma hissi yaratabilir (Beddoe ve Murphy, 2004). Bu durum çalışanları tükenmişliğe götüren temel nedenlerden biri olarak görülmektedir. Lee vd. çalışmamızla benzer şekilde empatide ki azalışın duygusal tükenme puanında artışa neden olduğunu bulmuşlardır (Lee vd., 2003).

Kösal (2009) empatik eğilimdeki artışın; duygusal tükenme de azalmaya ve kişisel başarıda artmaya neden olabileceğini belirtmiştir (Kösal, 2009).

Sağlık kurumlarındaki personelin becerisi, istekliliği, iletişim yeteneği, görünümü ve davranışları güçlü bir ilişkinin geliştirilmesi ve memnuniyetinin sağlanması için oldukça önemlidir (Jap, 2001).

Beydoğan ve Kalyoncu (2017); empatinin hastaların memnuniyet düzeylerini olumlu yönde etkilediğini tespit etmişlerdir (Beydoğan ve Kalyoncu, 2017). Bu da; çalışanlarının empati kurarak hastalara bireysel olarak ilgi göstermelerinin hastaların psikolojisi üzerinde ne kadar etkili olduğunu göstermektedir.

Bu çalışmalardan farklı olarak; kişilerde empatinin artması ile tükenmişliğin de artacağını belirten yayınlara da rastlanmaktadır (Fields vd, 
2004; Duru, 2002). Fizyoterapi kliniklerine çoğunlukla ağrısı olan kişiler başvurmaktadır (Tütüncü ve Günay, 2011).

Ağrı sadece fizyolojik bir olay değil aynı zamanda duyusal, emosyonel ve davranışsal faktörleri içeren karmaşık bir durumdur.(Aytar, 2007). Dolayısı ile ağrıyı tedavi edecek kişilerin mutlu hasta ile sağlıklı iletişim kurabilen ve tükenmişlik yaşamayan kişiler olmasının tedavi sonuçlarını da olumlu yönde etkileyebileceğini düşünmekteyiz.

Aksoy vd. (Aksoy, Taşpınar, Okur, Kurt, Taşpınar, 2017) yaptıkları bir çalışmada farklı alanlarda çalışan fizyoterapistlerin yüksek oranda mobbinge maruz kaldığını ve bu nedenle iş üretkenliğinin olumsuz olarak etkilendiğini bildirmiştir. Benzer şekilde, Yasacı vd. (Yasacı, Mustafaoğlu, Zirek, Çelik, 2016) akademik personelin iş doyumunun yüksek, kamu personeli ve özel sektör personellerinin ise düşük olduğunu göstermişlerdir.

Çalışma saatleri, çalışma ortamı gibi mesleki memnuniyeti etkileyen faktörlerin düzeltilerek çalışanların memnuniyet düzeyi arttırılırsa, hasta memnuniyetinin de artabileceğini düşünmekteyiz.

Sağlık sektöründe kalite anlayışının gelişmesiyle birlikte, hizmet kalitesinin en önemli göstergelerinden biri olan "hasta memnuniyeti" terimi de önem kazanmaya başlamıştır (Zaim, Tarım, 2010).

Sağlık sektöründe hasta memnuniyetinin artması için fizyoterapi hizmetlerinin de geliştirilmesi önemlidir. Hastaların tedavi aldıkları süre içerisinde tedaviden duydukları memnuniyet, tüm hastane hizmetleri ile ilgili memnuniyetlerini de etkileyen en önemli faktördür (Evans, Martin, Winslow, 1998).

Tüzün vd. (Tüzün, Eker, Daşkapan, 2009) fizyoterapist ile iletişimin, fizyoterapistin ilgisinin, açıklayıcı bilgi vermesinin ve soruları anlaşılabilir olarak yanıtlamasının hasta memnuniyeti üzerinde belirleyici faktörler olduğunu göstermiştir.

Hasta memnuniyetinin sağlanması ya da eksiklerin saptanması oldukça önemlidir. Bu kurumun kendini değerlendirmesini sağlar, üstünlük ve zayıflıklarını ortaya koyar, ayrıca memnuniyeti yeterli seviyede olmayanların geri bildirimlerini alarak hizmetin iyileştirilmesine fırsat sunar.

Buda sağlık sektörünü daha ileri seviyelere taşımaya yardımcı olur (Hekimoğlu, Tekiner, Peker, 2015). 
Sağlık çalışanlarının tümünü temsil edebilecek örneklemde olmaması sadece Ankara ilinde ve özel sektörde çalışan fizyoterapistlerde yapılması çalışmamızın sınırlılıklarındandır.

Fizyoterapistlerin multidispliner ekibin bir parçası olduğu göz önüne alınacak olursa tüm sağlık çalışanlarının etkili iletişim kurulması ve tükenmişlik yaşamaması oldukça önemlidir. Sağlık çalışanlarının mutlu ve empati yeteneği yüksek kişiler olması hem hasta memnuniyetini hem de mesleki memnuniyeti arttırmaya yardımcı olacaktır.

\section{Sonuç}

Mesleki memnuniyetsizliklerin azaltılması, çalışma koşullarının fazla olduğu, iş yükünün yoğun olduğu kliniklerde çalışan fizyoterapistlerin, kurum şartları da göz önünde tutularak iş yükünü azaltmaya yönelik önlemler alınması oldukça önemlidir.

Ayrıca tükenmişliği etkileyen faktörlerin erken dönemde fark edilmesi ve önlemeye yönelik tedbirlerin alınması da oldukça yararlı olacaktır.

Empati ve empatik yaklaşımın kişilerin tükenmişlik ve mutluluk düzeyleri ile ilişkisi göz önünde bulundurulduğunda bu konuda hizmet içi eğitim programlarının veya seminerlerin daha sık düzenlenmesinin de önemli olduğunu düşünmekteyiz. 


\section{EXTENDED ABSTRACT}

\section{The Relationship Between Empathy Skills with Happiness and Burnout Level in Physiotherapists \\ *}

Ayça Aytar Tığlı

Başkent University

Nowadays many professional groups require face-to-face communication with people. Burnout is a syndrome that threatens people in occupations that require intense relationships with people and it usually occurs as a result of stress that cannot be coped. It puts physical, mental and emotional pressure on people's lives and creates burnout. Burnout affects both people and their working life negatively. Not only burnout but also dissatisfaction with the conditions of the working environment and professional dissatisfaction affect the working life and psychology of the employees so all of these prevent them from providing quality service. Therefore, it is very important that working people are not only physically well, but also spiritually well. Happiness have a protective effect against psychological disorders. Happiness is a concept that affects all aspects of human life. It is expressed as the positive emotions that one feels more than negative emotions and satisfaction from life. it is necessary to understand others to live happier and more fulfilled relationships. Empathic tendency is the determinant of the level of help. It includes the ability of individuals with problems to be affected by their emotional experiences by understanding their emotions. Therefore, there is a positive relationship between empathy and interpersonal communication and cooperation. Since physiotherapists may need to interact closely with their patients during the rehabilitation process, empathy and interpersonal communication and cooperation gain importance. However, the number of studies performed by physiotherapists remains limited. In this context, the aim of our study was to investigate the relationship between empathy and happiness and burnout in physiotherapists. 
The study population consisted of physiotherapists who were working in private hospitals in Ankara. 56 females and 34 males a total of 90 (age $x_{ \pm s s}=27.56 \pm 5.27$ year) physiotherapists were evaluated in our study.

Individuals who were actively working as a physiotherapist for at least 1 year were included, non-volunteers to participate in the study were excluded from the study.

Questionnaires applied with face to face method. Firstly, the height, weight, education and marital status of the individuals, the neighbourhood they worked in, their working time were recorded. The correlation between the variables was evaluated with "Pearson Correlation Analysis. Multiple step regression analysis was used to find the determinants of empathy skills. Statistical significance level was accepted as $\mathrm{p}<0.05$. Toronto Empathy Scale used to determine empathy skills, Short Form of Oxford Happiness Scale used to measure happiness and Short Form of Burnout Scale used to evaluate professional burnout levels. It was found that happiness was negatively correlated with burnout level $(\mathrm{r}=-0.678)$ and positively correlated with empathy skills $(r=0.212, p=0.045)$. Multiple stepwise regression analysis showed that happiness was a positive predictor of empathy $\left(R=0.212\right.$, $\left(R^{2}=0.045\right)$. In other words, as the happiness levels of individuals increase, burnout levels decrease, and empathy skills increase. Some personality traits are so important for some professions that interact directly with people. These characteristics of health care workers is also affected patients and treatment results. In our study, it was seen that happiness of physiotherapists was negatively related with burnout but positively associated with empathy ability. However; happiness had a decisive effect on empathy ability. In order to increase patient satisfaction in the health sector, it is important to develop quality of physiotherapy ministiration. The satisfaction of patients during treatment is the most important factor affecting their satisfaction with all hospital services. There are studies showing that communication with physiotherapist, interest of physiotherapist, giving patients explanatory information and answering patient's questions comprehensively are determinant factors on patient satisfaction. Ensuring patient satisfaction or detection of the missing is quite important. This enables the institution to evaluate itself, demonstrates its strengths and weaknesses, and provides the opportunity 
to improve the service by receiving feedback from those whose satisfaction is not enough. This helps to improve health services advanced levels. One of the limitations of our study is that our samples cannot represent all health workers. Our study was conducted only on physiotherapists working in Ankara and private sector. Considering that physiotherapists are part of the multidisciplinary team, it is very important that all healthcare workers communicate effectively and do not experience burnout. The fact that health workers are happy and have high empathy skills will help to increase both patient satisfaction and professional satisfaction. It is very important to reduce occupational dissatisfaction and to take measures to reduce the workload of physiotherapists working in clinics where work conditions are high, and workload is intensive. It will also be useful to recognize the factors affecting burnout in the early period and to take preventive measures.

\section{Kaynakça / References}

Akbaba, A., Türkmen, E., Birinci T. (2018). Fizyoterapistlerin çalışma ortamı ve koşulları ile mesleki memnuniyetlerinin incelenmesi. Sağlık Bilimleri ve Meslekleri Dergisi, 5(1), 1-5.

Aksoy, C. C., Taşpınar, B., Okur, İ., Kurt, G., Taşpınar, F (2017). Fizyoterapistlerde Mobbing Maruziyeti ve İş Üretkenliğinin İncelenmesi. Adnan Menderes Üniversitesi Sağllk Fakültesi Dergisi, 1(1), 20-27.

Aytar, A. (2007). Kas iskelet sistemi hastalıklarına bağlı Kronik ağrlların yaşam kalitesi üzerine olan etkileri. Yüksek Lisans Tezi. Sağlık Bilimleri Enstitüsü. Başkent Üniversitesi ,Ankara.

Beddoe, A. E. ve Murphy, S. O. (2004). Does mindfulness decrease stress and foster empathy amongnursing students? Journal of Nursing Education, 43(7), 305-312.

Beydoğan, G. Ş. ve Kalyoncuoğlu, S. (2017). Fizik tedavi ve rehabilitasyon hizmeti alan hastaların kalite algılarının memnuniyetleri üzerindeki etkisi:Kırşehir ilinde bir araştırma. 2nd International Congress On Political, Economic And Social Studies, 19-22.

Çapri, B. (2006). Tükenmişlik ölçeğinin Türkçe Uyarlaması: Geçerlik ve güvenirlik çalışması. Mersin Üniversitesi Eğitim Fakültesi Dergisi, 2(1), 62-77. 
Çapri, B. (2013). Tükenmişlik ölçeği kısa formu ile eş tükenmişlik ölçeği kısa formu'nun Türkçe uyarlaması ve psikoanalitik varoluşçu bakış açısından mesleki ve eş tükenmişlik ilişkisi. Kuram ve Uygulamada Eğitim Bilimleri, 13(3), 1393-1418.

Doğan, T., Akıncı, Ç. N.(2011). Oxford mutluluk ölçeği kısa formunun Türkçe uyarlaması: Geçerlik ve güvenirlik çalışması. Türk Psikolojik Danışma ve Rehberlik Dergisi, 4 (36), 165-172.

Dökmen, Ü. (1999). Sanatta ve günlük yasamda iletisim çatısmaları ve empati, İstanbul:Sistem Yayınevi.

Duru, E. (2002). Öğretmen adaylarında empatik eğilim düzeyinin bazı psikososyal değişkenler açısından incelenmesi. Pamukkale Üniversitesi Eğitim Fakültesi Dergisi, 2(12), 21-35.

Evans, L. M., Martin, L. M., Winslow, H. E. (1998). Nursing care and patient satisfaction, American Journal of Nursing, 98(12), 57-59.

Fields, S. K., Hojat, M., Gonnella, J. S., Mangione, S., Kane, G., Magee, M. (2004). Comparisons of nurses and physicians on an operational measure of empathy. Evaluation \& The Health Professions, 27(1), 80-94.

Hekimoğlu, L., Tekiner, A.S. ve Peker, G. C. (2015) Kamuya ait bir eğitim ve araştırma hastanesinde ayaktan ve yatan hasta memnuniyeti. Konuralp Tip Dergisi, 7(1), 1-5.

Jap, S. D. (2001). The strategic role of the sales force in developing customer satisfaction across the relationship lifecycle. Journal of Personal Selling $\mathcal{E}$ Sales Management, 21(2), 95-108.

Kılınç, M. ve Uludağ A. (2017). Sağlık çalışanlarının empatik eğilim düzeyinin saldırgan davranış düzeyleri ile ilişkisi. Gaziantep University Journal of Social Sciences, 16(3), 809-825.

Kösal, H. (2009). Hemşirelerin empatik eğilim ve tükenmişlik düzeyleri arasındaki ilişkinin belirlenmesi. Yüksek Lisans Tezi, Dokuz Eylül Üniversitesi Sağlık Bilimleri Enstitüsü. İzmir.

Lee, H., Song, R., Cho, Y. S., Lee, G. Z. ve Daly, B. A. (2003). Comprehensive model for predicting burnout in korean nurses. Journal of Advanced Nursing, 44(5), 534-545.

Özdemir, Y. ve Koruklu, N. (2011). Üniversite öğrencilerinde değerler ve mutluluk arasındaki ilişkinin incelenmesi. Yüzüncü Yıl Eğitim Bilimleri Dergisi , 8(1), 190-210. 
Tarakcı, E., Tütüncüoğlu, F. ve Tarakcı, D. (2012). Özel eğitim ve rehabilitasyon alanında çalışan meslek elemanlarının öz-yeterlilik ve tükenmişlik düzeylerinin incelenmesi. Fizyoterapi Rehabilitasyon, 23(1), 26-35.

Totan, T., Doğan, T. ve Sapmaz, F. (2012). The Toronto Empathy Questionnaire: Evaluation of psychometric properties among Turkish university students. Egitim Arastirmalarn-Eurasian Journal of Educational Research, 46, 179-198.

Tütüncü, R. ve Günay, H. (2011). Kronik ağrı, psikolojik etmenler ve depresyon. Dicle Tip Dergisi, 38(2), 257-262.

Tüzün, E. H., Eker, L. ve Daşkapan, A. (2009). Fizik tedavi poliklinikleri için hasta memnuniyet ölçeği: güvenirliği ve geçerliği. Fizyoterapi Rehabilitasyon, 20(1), 09-16.

Yasacı, Z., Mustafaoğlu, R., Zirek, E. ve Çelik, D. (2017). Fizyoterapistlerin Mezuniyet Sonrası Aldığı Eğitim, İş Doyumu Ve Mesleki Tükenmişlik Düzeylerinin Araştırılması. Mesleki Bilimler Dergisi, 6(3), 719 729.

Zaim, H. ve Tarım, M. (2010). Hasta memnuniyeti: Kamu hastaneleri üzerine bir alan araştırması. Sosyal Siyaset Konferansları,591-24.

\section{Kaynakça Bilgisi / Citation Information}

Tiğll-Aytar, A. (2019). Fizyoterapistlerde empati becerisinin mutluluk ve tükenmişlik düzeyi ile ilişkisi. OPUS-Uluslararası Toplum Araştırmalar Dergisi, 14(20), 1011-1024. DOI: 10.26466/opus.600820 